\title{
Comparative Hemodynamic Effects of Selective Superior Mesenteric Arterial and Peripheral Intravenous Glucagon Infusions
}

\author{
Cameron D. Wright, M.D.,' ANDris Kazmers, M.D., \\ Walter M. Whitehouse, JR., M.D., and James C. Stanley, M.D. \\ Department of Surgery, Division of Peripheral Vascular Surgery, University of Michigan \\ Medical School, Ann Arbor, Michigan 48109
}

Submitted for publication January 23, 1984

\begin{abstract}
This experiment was designed to determine whether any hemodynamic benefits attend administration of equal pharmacologic doses of glucagon $(1 \mu \mathrm{g} / \mathrm{kg} / \mathrm{m}$ ) by continuous intravenous infusion (Group I, $n=6$ ) versus selective intraarterial infusion (Group II, $n=6$ ) via the superior mesenteric artery (SMA) in dogs. Cardiac output, heart rate, mean arterial pressure, total peripheral resistance, pulmonary vascular resistance, superior mesenteric artery flow (SMAQ), SMA vascular resistance, and portal venous pressure were measured at baseline (BL) and at 5, 15,30, and 45 min during glucagon infusion. SMAQ virtually doubled at $5 \mathrm{~min}$ from a baseline of $570 \pm 60 \mathrm{ml} / \mathrm{min}$ to $1158 \pm 146$ $\mathrm{ml} / \mathrm{min}$ in Group I $(P<0.001)$, and from a baseline of $527 \pm 171$ to $1018 \pm 331 \mathrm{ml} / \mathrm{min}$ in Group II $(P<0.002)$. SMAQ was significantly higher in Group I at 30 and $45 \mathrm{~min}$ compared to Group II $(P<0.03)$ despite similar peripheral plasma glucagon levels. SMA vascular resistance was significantly lowered in both groups, with a greater reduction occurring during intravenous glucagon administration at $45 \mathrm{~min}(P<0.05)$. Changes in systemic hemodynamic parameters, as well as glucagon and glucose levels were not statistically different between Groups I and II at any time period. Glucagon is a potent mesenteric vasodilator and the resultant profound splanchnic hemodynamic effects are as marked during intravenous administration as during selective SMA infusion. (1) 1985 Academic Press, Inc.
\end{abstract}

The potential usefulness of mesenteric vasodilators in treating acute mesenteric ischemia became apparent from earlier reports of the efficacy of an aggressive therapeutic approach that included the adjunctive usc of intraarterial papaverine [3]. Unfortunately, papaverine may not be a very potent mesenteric vasodilator $[1,11]$, and this agent may be ineffective when the superior mesenteric artery (SMA) becomes occluded proximal to collateral vessels $[16,19]$. Furthermore, intraarterial papaverine has been reported to have a deleterious effect on oxygen consumption in an animal model of acute mesenteric ischemia [14]. Such disadvantages and the requirement that papaverine must be administered intraarterially in order to be effective, have led to studies of other potential splanchnic arterial vasodilators. Included

\footnotetext{
${ }^{1}$ Present address: Department of Surgery, Massachusetts General Hospital, 55 Fruit Street, Boston, Mass. 02114.
}

among such agents has been glucagon which has been shown to improve survival in a rodent model of acute mesenteric ischemia involving temporary complete SMA occlusion [10].

Previous studies have verified that glucagon administered intravenously increases SMA flow out of proportion to the increase in cardiac output induced by this agent $[9,18]$. Furthermore, we have documented that this increase in SMA flow is of a nonshunt, nutritive nature [9], in contrast to previous speculation that increases in SMA flow resulted from increased arteriovenous shunting $[7,8,21]$. The current work, representing an extension of earlier studies from our laboratory, assessed the comparative splanchnic hemodynamic effects of equal pharmacologic doses of glucagon administered by selective intraarterial infusion compared with those effects following parenteral intravenous infusion. Data from this study might have an impact on future clinical trials evaluating 
glucagon as a possible therapeutic agent for treating acute mesenteric ischemia.

\section{MATERIALS AND METHODS}

Twelve healthy adult dogs, weighing 22 to $35 \mathrm{~kg}$, were anesthetized using intravenous pentobarbital $(30 \mathrm{mg} / \mathrm{kg})$ with supplemental doses $(5 \mathrm{mg} / \mathrm{kg})$ administered as needed during preparation of the subjects. No experimental manipulations or measurements were performed until a stable hemodynamic baseline was attained 30 to $40 \mathrm{~min}$ after either initial or supplemental doses of pentobarbital were administered [12]. Additional pentobarbital was not administered after this baseline was achieved. Dogs were intubated and mechanically ventilated in order to maintain physiologic arterial blood gases and normal blood $\mathrm{pH}$ (7.34-7.44). An esophageal probe monitored core temperature which was maintained with the use of an external heat source in all animals. Lactated Ringer's solution was infused at a rate of $25 \mathrm{ml} / \mathrm{kg} / \mathrm{hr}$ during the course of the experiment. A carotid arterial catheter, a jugular central venous catheter, and a 7 French thermodilution Swan-Ganz catheter were properly positioned. After midline laparotomy, the superior mesenteric artery was exposed and a carefully precalibrated, nonoccluding electromagnetic flow probe was placed about its origin and appropriately zeroed for each subject. A 21-gauge polyethylene catheter for intraarterial glucagon administration was inserted into one of the mesenteric branches, and threaded into the SMA approximately 1 to $2 \mathrm{~cm}$ from its origin, proximal to all branches. An 18-gauge polyethylene catheter was threaded into the portal vein through a pancreaticoduodenal venous branch. The abdominal viscera were returned to the peritoneal cavity, and the abdominal incision was reapproximated prior to hemodynamic testing.

Central venous, pulmonary artery, carotid arterial, and portal venous pressures were continuously recorded using pressure transducers connected to a multichannel recorder.
Cardiac output was measured by thermodilution. SMA flow was measured using a square wave flowmeter and was continuously recorded. Heart rate and pulmonary capillary wedge pressure were determined, and blood samples were withdrawn through the central venous catheter for venous glucose and glucagon level measurements. Plasma glucose was determined by a standard automated hexokinase method. Plasma glucagon was determined by radioimmunoassay [20].

Cardiac output $(\mathrm{CO}-\mathrm{liter} / \mathrm{m})$, mean arterial pressure (MAP-mm $\mathrm{Hg}$ ), central venous pressure (CVP-mm $\mathrm{Hg}$ ), mean pulmonary artery pressure (PAP- $\mathrm{mm} \mathrm{Hg}$ ), pulmonary vascular resistance $(\mathrm{PVR}=\mathrm{MPAP}$ - PCWP/CO X 79.9-dynes-sec/ $\mathrm{cm}^{5}$ ), total peripheral resistance $(T P R=M A P-C V P /$ $\mathrm{CO} \times 79.9$-dynes-sec/ $/ \mathrm{cm}^{5}$ ), SMA blood flow (SMAQ-ml/m), portal venous pressure (PVP-mm $\mathrm{Hg}$ ), SMA resistance (SMAR $=$ MAP - PVP $/ \mathrm{SMAQ}$ (liter $/ \mathrm{m}) \times 79.9-$ dynes-sec/ $/ \mathrm{cm}^{5}$ ), and an estimate of left ventricular stroke work [LVSW $=$ (MAP - PCWP) $\times \mathrm{CO} / \mathrm{HR}$ ] were measured or calculated in the usual fashion at baseline (BL) and at $5,15,30$, and 45 min during infusion of $1 \mu \mathrm{g} / \mathrm{kg} / \mathrm{m}$ glucagon in a $45-\mathrm{ml}$ volume of normal saline using a calibrated Harvard infusion pump. Infusions were administered through either a peripheral vein in six dogs (Group I) or directly into the SMA in six additional dogs (Group II). Data were subjected to statistical analysis using the University of Michigan MIDAS statistical program. The paired $t$ test was used for evaluation of differences within a Group, with the unpaired $t$ test and Mann-Whitney $U$ median tests were used for assessing differences between Groups I and II. Creation of correlation matrices with calculation of the Pearson product-moment correlation coefficients were also used in the statistical analyses.

\section{RESULTS}

None of the baseline parameters measured in this study were significantly different between Group I receiving glucagon intrave- 
nously compared to Group II receiving glucagon intraarterially.

During glucagon infusion CO did not differ between the two groups (Table 1), although changes within each group did occur. $\mathrm{CO}$ was increased significantly in both Groups at $5 \min (P<0.03)$, but subsequently was not significantly different from control values. Left ventricular stroke work was decreased by $15 \mathrm{~min}$ in both groups $(P<0.02)$, and subsequently remained lower than baseline values. Heart rate significantly increased throughout the infusions of glucagon regardless of the route of administration $(P<0.005)$. The degree of tachycardia was not different between the groups at any time period.

Mean arterial pressure decreased significantly following $15 \mathrm{~min}$ of intravenous infusion $(P<0.02)$, and remained below the baseline of $133 \mathrm{~mm} \mathrm{Hg}$, reaching $110 \mathrm{~mm}$ $\mathrm{Hg}$ at $45 \mathrm{~min}$. Mean arterial pressure following intraarterial administration was also diminished at $15 \mathrm{~min}(P<0.01)$, and likewise remained lower than control values for the remainder of the infusion, dropping from a baseline of 129 to $105 \mathrm{~mm} \mathrm{Hg}$ at $45 \mathrm{~min}$.

TPR decreased significantly throughout intravenous glucagon administration in Group I $(P<0.04)$. Total peripheral vascular resistance decreased at $5 \mathrm{~min}$ in Group II and remained lower than control values at $45 \mathrm{~min}$ in the group receiving glucagon intraarterially $(P<0.03)$. Differences in TPR between the two groups never attained significance. There was no significant change in mean pulmonary artery pressure, or pulmonary vascular resistance within or between the groups.

Mesenteric hemodynamics were markedly altered in both groups (Table 2). Intravenously administered glucagon doubled SMA blood flow from a baseline of $570 \pm 60 \mathrm{ml} /$ $\mathrm{m}$ to $1158 \pm 146 \mathrm{ml} / \mathrm{m}$ by $5 \mathrm{~min}(P<0.001)$. This increase in SMAQ persisted throughout intravenous drug infusion. Similarly, intraarterial glucagon nearly doubled SMA flow ( $P$ $<0.002$ ), but there appeared to be a less sustained response to glucagon in this group (Table 2). At the 30- and 45-min periods,

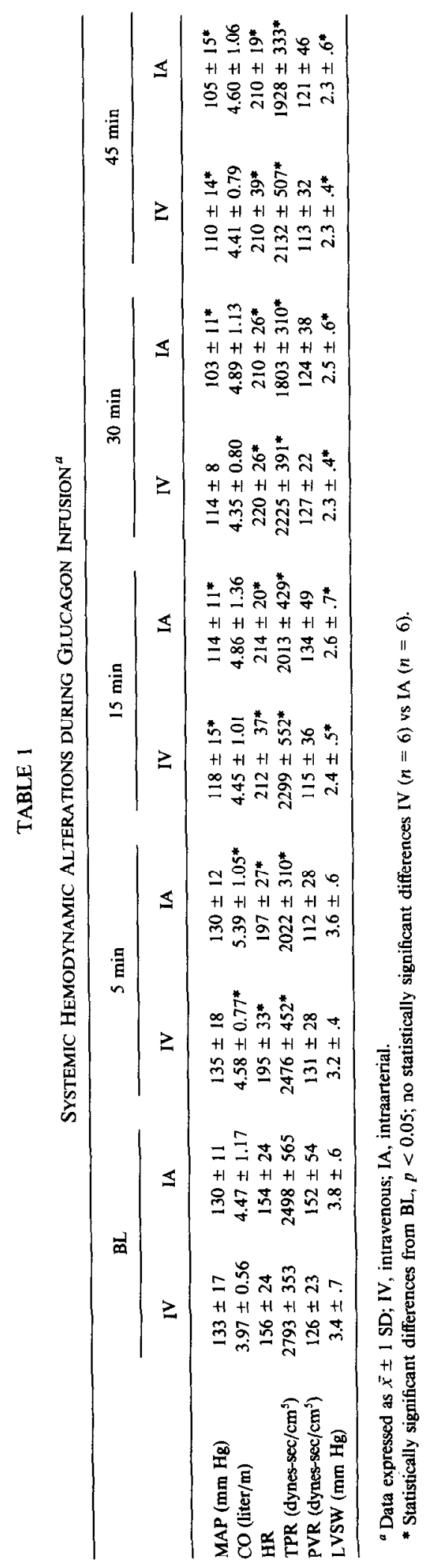




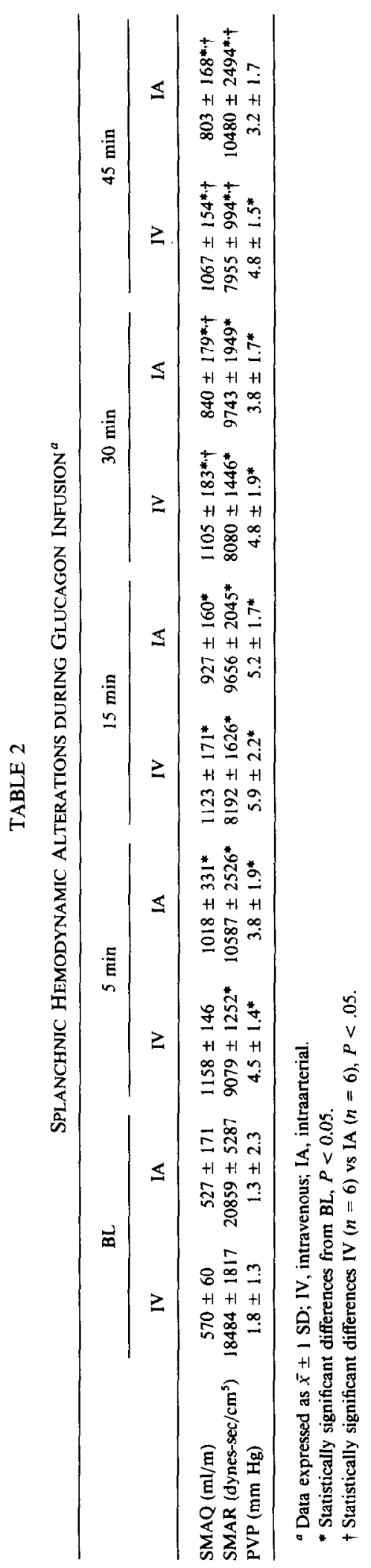

SMAQ was significantly greater in dogs receiving glucagon intravenously compared to those receiving the drug intraarterially $(P<0.03)$, and the difference in SMAQ between groups already approached significance as early as $15 \min (0.05<P<0.10)$. Reductions of SMAR were present in both groups throughout glucagon infusion $(P<0.01)$. SMAR was significantly lower at $45 \mathrm{~min}$ in the dogs receiving glucagon intravenously ( $P$ $<0.05$ ) compared with those receiving intraarterial glucagon.

The rise in portal venous pressure, thought to reflect increased SMAQ $[9,11]$, not necessarily arteriovenous shunting, was higher than control values $(P<0.03)$ in Group I, and was also higher than controls during intraarterial administration in Group II until $45 \mathrm{~min}$ when the values were not different from controls.

Glucose levels were elevated above control values throughout the study within both groups, but there was no difference in the degree of hyperglycemia achieved between the two groups (Table 3). Despite the minor differences in splanchnic hemodynamics between the two groups, no difference in blood glucagon levels occurred between the two methods of glucagon administration at the dosage level used in this study. Within each group over the course of study, glucagon levels correlated directly with SMAQ, PVP, $H R$, and glucose levels and inversely with TPR, SMAR, and LVSW $(P<0.05)$.

\section{DISCUSSION}

The purpose of this experiment was to assess the splanchnic vasoactive effects of glucagon administered intravenously compared to direct intraarterial SMA administration. Others have suggested that intraarterial administration of glucagon may provide a beneficial vasodilatory effect in the management of nonocclusive mesenteric ischemia $[6,22,24]$. Data from the present canine study supports the conclusion that intravenous glucagon in pharmacologic doses is as effective in increasing total SMA flow and 


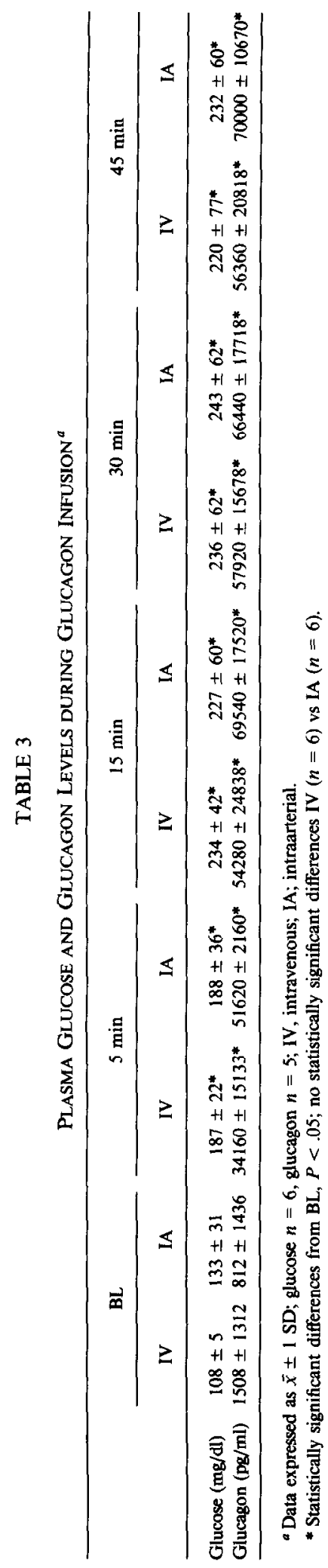

reducing splanchnic vascular resistance as is selectively administered glucagon. If one were to use glucagon as an adjunct in the clinical treatment of acute mesenteric ischemia, there might be no advantage to infusion of glucagon directly into the SMA compared with simple parenteral intravenous administration. Further, the potentially deleterious side effects of hyperglycemia and tachycardia resulting from intravenous glucagon administration were equally evident in this study during intraarterial infusion.

The rationale for the use of vasodilators in treating mesenteric ischemia relates primarily to the presence of reversible vasospasm. Lauffman introduced the concept of vascular spasm persisting after intestinal vascular occlusion $[16,19]$. Turner reported significantly reduced intestinal blood flow following relief of both mesenteric arterial and venous occlusions [23]. Vasoconstriction has also been postulated to play an important role in the pathogenesis of nonocclusive mesenteric ischemia $[1-3,6,14,15,16,19,24]$. Although controlled trials demonstrating improved survival of patients with acute mesenteric ischemia treated with vasodilators are nonexistent, the adjunctive use of such agents appears theoretically sound. Clearly, the best vasodilator has not been determined, but intravenous glucagon appears to be a suitable agent for study in humans.

The hemodynamic effects of glucagon, in pharmacologic doses, include positive inotropic and chronotropic actions as well as reductions in LVSW such as documented in the current study $[9,18]$. Glucagon increases celiac and superior mesenteric blood flow, as well as liver perfusion by increasing both portal venous and hepatic arterial blood flow $[13,18]$. The hormone significantly enhances intestinal villous tip blood flow, and effectively increases SMA blood flow despite SMA stenoses and digoxin-induced vasoconstriction $[4,17]$. Glucagon-induced reductions in intestinal motility may theoretically lower the bowel's energy requirements, and the accompanying inhibition of gastric, biliary, and pancreatic secretion may be beneficial in 
lessening the so called "enzymatic phase" of intestinal injury associated with vascular insufficiency $[5,15]$.

Recently, we have shown that intravenously administered glucagon improves survival in a rat model of acute mesenteric arterial insufficiency [10]. It would seem that the adjunctive use of intravenous glucagon in pharmacologic doses deserves study in clinical instances of acute mesenteric ischemia. This agent has been safely administered to humans [25]. The intravenous route of administration would allow rapid initiation of adjunctive therapy prior to obtaining confirmatory angiography in patients suspected of having acute mesenteric ischemia, and theoretically would not mandate prolonged use of an indwelling arterial catheter. The results from this canine study suggest that intravenously administered glucagon is at least as effective as glucagon administered by a select intraarterial route in increasing mesenteric blood flow and reducing mesenteric vascular resistance.

\section{REFERENCES}

1. Athanasoulis, C. A., Wittenberg, J., Bernstein, R., and Williams, L. F. Vasodilatory drugs in the management of nonocclusive bowel ischemia. Gastroenterology 68: 146-150, 1975.

2. Boley, S. J., Regan, J. A., Tunick, P. A., Everhard, M. E., Winslow, P. R., and Veith, F. J. Persistent vasoconstriction-A major factor in nonocclusive mesenteric ischemia. Curr. Top. Surg. Res. 3: 425433, 1971.

3. Boley, S. J., Sprayregan, S., Siegelman, S. S., and Veith, F. J. Initial results from an aggressive roentgenological and surgical approach to acute mesenteric ischemia. Surgery 82: 848-855, 1977.

4. Bond, J. H., and Levitt, M. D. Use of microspheres to measure small intestinal villus blood flow in the dog. Amer. J. Physiol. 236: 577-583, 1979.

5. Fasth, S., and Hulten, L. The effect of glucagon on intestinal motility and blood flow. Acta. Physiol. Scand. 83: 169-173, 1971.

6. Habboushe, F., Wallace, H. W., Nusbaum, M., Baum, S., Dratch, P., and Blakemore, W. S. Nonocclusive mesenteric vascular insufficiency. Ann. Surg. 180: 819-822, 1974.

7. Jensen, H. E.: The effect of glucagon on pressure and oxygen saturation of splanchnic venous blood. Amer. J. Dig. Dis. 11: 447-452, 1966.

8. Jensen, H. E., and Necheles, H. Hemodynamic effects of glucagon in the splanchnic area. Ill. Med. J. 130: 49-53, 1966.

9. Kazmers, A., Wright, C. D., Whitehouse, W. M., Jr., Zelenock, G. B., Lindenauer, S. M., and Stanley, J. C. Glucagon and canine mesenteric hemodynamics: Effects on superior mesenteric arteriovenous and nutrient capillary blood flow. J. Surg. Res. 30: 372$378,1981$.

10. Kazmers, A., Zwolak, R., Appleman, H. A., Whitehouse, W. M., Jr., Wu, S. C., Zelenock, G. B., Cronenwett, J. L., Lindenauer, S. M., and Stanley, J. C. Pharmacologic interventions in an acute mesenteric ischemia: Improved survival with intravenous glucagon, methylprenisolone, and prostacyclin. $J$. Vasc. Surg. 1: 472-481, 1984.

11. Kazmers, $\Lambda$. Autoregulatory escape from the vasodepressor activity of intraarterial papaverine. Surg. Forum 32: 201-204, 1981.

12. Kazmers, A., Whitehouse, W. M., Jr., Zelenock, G. B., Cronenwett, J. L., Lindenauer, S. M., and Stanley, J. C. Early derangements of arteriovenous anastomotic and capillary blood flow in the canine hindlimb induced by supplemental pentobarbital anesthesia. J. Surg. Res. 36: 102-107, 1984.

13. Kock, N. G., Roding, B., Hahnloser, P., Tibblin, S., and Schenk, W. G., Jr. The effect of glucagon on hepatic blood flow. An experimental study in the dog. Arch. Surg. 100: 147-149, 1970.

14. Lanciault, G., Fang, W. F., Jacobson, E. D., and Bowen, J. C. Evaluation of potential agents for treatment of nonocclusive mesenteric ischemia in the dog. Circ. Shock 3: 239-246, 1976.

15. Lauffman, H. Discussion. In L. F. Williams, Jr., L. F. Anastasia, C. A. Hasiotis, M. A. Bosniak, and J. J. Byrne, Experimental nonocclusive mesenteric ischemia. Therapeutic observations. Am. J. Surg. 115: 82-88, 1968.

16. Laufman, H., and Method, $H$. The role of vascular spasm in recovery of strangulated intestine. Surg. Gynecol. Obstet. 85: 675-686, 1947.

17. Levinsky, R. A., Lewis, R. M., Bynum, T. E., and Hanley, J. G. Digoxin induced intestinal vasoconstriction. The effects of proximal arterial stenosis and glucagon administration. Circulation 52: 130$136,1975$.

18. Madden, J. J. Jr., Ludewig, R. M., and Wangensteen, S. L. Effects of glucagon on the splanchnic and the systemic circulation. Amer. J. Surg. 122: 85-90, 1971.

19. Martin, W. B., Laufman, H., and Tuell, S. W. Rationale of therapy in acute vascular occlusions based upon micrometric observations. Ann. Surg. 129: 476-493, 1949.

20. Pek, S., Fajans, SS, Floyd, J. C., Jr., Knopf, R. F., 
and Conn, J. W. Failure of sulfonylureas to suppress plasma glucagon in man. Diabetes 21: 216-223, 1972.

21. Proctor, J. H., Wood, J. J., and Palladino, W. G. The effect of glucagon on hepatic cellular energetics during a low flow state. Surgery 87: 369-374, 1980.

22. Schwaiger, M., Fondacaro, J. D., and Jacobson, E. D. Effects of glucagon, histamine, and perhexiline on the ischemic canine mesenteric circulation. Gastroenterology 77: 730-735, 1979.

23. Turner, M. D., Neely, W. A., and Barnett, W. O.
The effects of temporary arterial venous, and arteriovenous occlusion upon intestinal blood flow. Surg. Gynecol. Obstet. 108: 347-350, 1959.

24. Ulano, H. B., Treat, E., Shanbour, L. E., and Jacobsen, E. D. Selective dilation of the constricted superior mesenteric artery. Gastroenterology 62: 3947, 1972.

25. VanderArk, G. R., and Reynolds, E. W., Jr. Clinical evaluation of glucagon by continuous infusion in the treatment of low cardiac output states. Amer. Heart J. 79: 481-487, 1970. 